\title{
Research on the Application of Computer in the Design of Arts and Crafts
}

\author{
Zhengjuan $\mathrm{Hu}^{1}$ \\ ${ }^{1}$ Jingdezhen Ceramic University, Jingdezhen, Jiangxi, ZIP code, China
}

\begin{abstract}
Firstly, this paper expounds the design methods of traditional arts and crafts, including the traditional design methods of sculpture crafts, glass crafts and ceramic crafts. Then it analyzes the advantages of computer technology in the design of arts and crafts, including improving the product performance of arts and crafts, improving the design interest of arts and crafts designers and improving the modern flavor of arts and crafts; then it expounds the application of computer technology in different stages of arts and crafts design in detail, including the early preparation, concrete implementation, design scheme optimization and in-depth design stage; Finally, it analyzes the specific application of computer technology in arts and crafts design, including the application of computer technology in sculpture crafts design, glass crafts design and ceramic tea set modeling design.
\end{abstract}

\section{Introduction}

Arts and crafts retain the aesthetic feeling of art and have the practicality of handicrafts. It has high aesthetics and practicality, and is more easily accepted by the audience. It is the product of the integration of spirituality and aesthetics under the needs of the audience, and organically combines art with manual crafts. Traditional forms of arts and crafts can no longer meet the needs of modern people for arts and crafts. It is necessary to combine the characteristics of the times, use modern technical means and integrate modern elements, so as to produce brandnew modern arts and crafts that are needed and accepted by the society. The design of modern arts and crafts can not be separated from the assistance of computer technology. Arts and crafts are both practical and ornamental works of art. There are many kinds of arts and crafts, including arts and crafts, woodenware, lacquerware, metal crafts, glass crafts, sculpture crafts and ceramic crafts, which can be seen everywhere in people's daily life and work.

\section{Design Method of Traditional Arts and Crafts}

\subsection{Traditional design methods of sculpture crafts}

Traditional design methods of sculpture crafts are particularly troublesome and prone to many defects. In the lending stage of design and production, small samples of sculpture crafts need to be made by hand. In this process, it is necessary to select clay, paper pulp, gypsum or sculpture clay which are easy to be molded, which is complicated and time-consuming, or the designer's ideas are presented on paper to draw a draft drawing of arts and crafts to be manufactured, which will also produce more time cost. Then, the designer needs to make the sculpture clay sculpture according to the finished draft or handicraft sample, and replace the clay sculpture with materials such as resin or gypsum. We also call this process the turnover in the process of making the sculpture handicraft. The traditional sculpture creation cycle is very long, the design and manufacturing process is very complicated and the design and manufacturing process is extremely cumbersome. It takes a long time and more money to support the design and manufacturing of sculpture crafts, and the professional requirements of designers are also high. In the initial design stage of sculpture handicraft, it is necessary to modify the handicraft sample many times to achieve the best effect. Compared with other crafts, the design and production process of sculpture crafts takes longer time, and the workload of design and production is relatively large. Generally, sculptors will participate more in the design process, paying attention to the production of small samples and drafts of sculpture crafts, but sculptors will not participate too much in the production process. In this way, even if the design is no better and the samples of sculpture crafts are no better, the finished sculpture crafts may not achieve the expected results. The disconnection between design and the production process of sculpture crafts has a negative impact on the molding of sculpture crafts[1].

\subsection{Traditional design method of glass crafts}

In the process of designing and manufacturing traditional glass crafts, the real needs of the market and audience 
customers will be investigated, and then the overall design scheme of glass crafts will be determined according to the survey results. It is necessary to select suitable processing facilities and techniques for making materials before drawing creative plane sketches, and then use professional techniques to make glass handicrafts. There are two ways to make traditional handmade glass, including "grafting" and "changing while doing". In the traditional form, when dewaxing and casting colored glaze, the corresponding plane design drawing should be drawn first, and then the three-dimensional model should be made according to the specific design drawing. It needs to go through a variety of procedures, including turning over the impression, pouring wax solution, trimming the corresponding wax mold, wrapping it with gypsum, dewaxing at high temperature, injecting glass frit into the molded gypsum mold, then firing finally, and stripping the gypsum mold after firing and molding. A series of treatments, including grinding, sandblasting, polishing, etc., are carried out on the fired glass, and the whole manufacturing process takes a long time, which also prolongs the design cycle.

\subsection{Traditional design method of ceramic crafts}

In the design process of traditional ceramic handicrafts, firstly, designers need to design ceramic decoration and ceramic modeling, and then show the concrete design in the form of hand-drawn drawings, and make ceramic physical models according to the drawn design drawings. In the process of designing and manufacturing this kind of ceramic handicraft, the designer's professional skills and experience are required to be high[2]. The designer needs to hand-painted and hand-made in the whole process, and the design and production process is complicated and difficult. At the same time, the selected raw materials will also affect the designer's design and production. Once there are any problems in the design process, it is necessary to modify them in time, so as to finally determine the design draft, ensure the feasibility of the design scheme and ensure that the design effect can reach the expectations. The molding process limits and affects the design and manufacture of ceramic handicrafts. Because of too many restrictions, it is difficult for designers to break through innovation in the design of ceramic handicrafts. The design of traditional ceramic crafts is limited by the molding process. When manufacturing ceramic crafts, it is necessary to make a middle mold first, and select the manufacturing methods of clay molding and turning. At this time, the shrinkage after firing and drying should be considered, and then the ceramic mold should be designed and manufactured. The design and production of traditional ceramic crafts pay more attention to the decoration part, and pay more attention to the treatment of three-dimensional sculpture of three-dimensional ceramics. Generally speaking, the relief decoration on ceramic sculpture crafts is treated by means of marking, engraving and printing, which can make ceramic crafts more hierarchica.

\section{Advantages of Computer Technology in the Design of Arts and Crafts}

\subsection{Improve the product performance of arts and crafts}

The practical value and artistry of arts and crafts including glass, ceramics and sculptures should be considered in the design process, which requires designers to have sufficient knowledge of the processing regularity of arts and crafts and the materials of processing tools and crafts. Using computer technology as an aid, better design of arts and crafts is conducive to improving the product performance of arts and crafts. In the design of arts and crafts, the use of computer aided design can incorporate modern elements, which improves the quality, practicality and appreciation of arts and crafts. Three-dimensional digital technology is gradually increasing in assisting the design of arts and crafts. Computer can be used as a medium to simulate the actual effect of arts and crafts design. Designers are no longer restricted by the physical layer, and can use computers to split, reorganize and adjust the building models of handicrafts. The traditional form has been broken because of the inconvenience of observing the arts and crafts due to their large size or small size, which greatly improves the product performance of arts and crafts[3].

\subsection{Enhance the design interest of arts and crafts designers}

The design process of traditional arts and crafts is cumbersome, and the designer's design ideas are limited. In the design process, most of them are repetitive work, boring and boring, and the designer's enthusiasm gradually dissipates. Using computer technology to assist the design of arts and crafts can simplify the design process, embody the designer's unconstrained ideas, and the design process is simple and interesting, which greatly increases the enthusiasm of design. In the design process of arts and crafts, the computer technology can make the drawing work simpler, at the same time, the drawing data is not prone to errors[4]. Once any problems appear in the design process, they can be solved in time. The computer can be used to search the design records, adjust and modify the completed drawings, and the divergent creative thinking of the designer becomes a reality. Once the designer generate gives creative inspiration, the computer can be used for drawing, which greatly increases the designer's design enthusiasm. With the help of computer technology, the process of creating and designing arts and crafts becomes simpler. Designers can use computers to design different styles and styles, adjust the angles, sizes, positions and components of works in time, and create other design alternatives by using computer technology such as splicing, cutting and reorganizing. It makes the designer's technique and style not limited by physical space, restores the designer's inspiration to the greatest extent, and effectively mobilizes the enthusiasm of design. 


\subsection{Enhance the modern flavor of arts and crafts}

Computer-aided design of arts and crafts can enhance the modern flavor of works. The design of arts and crafts can fully grasp the regularity of materials, tools and materials, and innovatively produce arts and crafts with rich patterns, shapes and structures. In the design of arts and crafts, the auxiliary function of computer technology is gradually strengthened, which can be used to design and manufacture ceramics, handicrafts, sculpture handicrafts and glass handicrafts, and at the same time integrate modern elements into the design process of arts and crafts. Glass crafts, ceramic crafts and sculpture crafts have a stronger modern fashion flavor. In the design process, various decorative techniques such as painting, relief, decal and printing can be combined, and then integrated into the designer's subjective thoughts to create modern arts and crafts with rich shapes[5].

\section{Application of Computer Technology in Different Stages of Arts and Crafts Design}

\subsection{Pre-preparation of arts and crafts design}

Computer technology runs through the whole process of arts and crafts design. In the early stage of design, computers can be used to sort out all kinds of materials and materials needed for hand design, and then assist designers to determine specific design ideas. Finally, designers use computer-related software to draw three views of design.

\subsection{Implementation of arts and crafts design}

The specific implementation stage of arts and crafts design can not be separated from the assistance of computer, and 3D design software is used frequently in this stage. In the process of using 3D software tools to model 3D models, it is necessary to combine the modeling features of arts and crafts with the three views drawn in the initial preparation stage[6]. In this process, designers need to master 3D software design tools skillfully. In the process of designing arts and crafts, if surface modeling is needed, 3D Rhino software is needed. Generally speaking, in the process of designing arts and crafts, when designing complex shapes, most of them will use computer Boolean operations and 3D scanning tools to generate shapes.

\subsection{Optimization of design scheme for arts and crafts}

The design scheme of arts and crafts can not be optimized without the help of computer. The designer needs to evaluate the original design scheme, find out the defects, and modify the design scheme based on the relevant requirements of the design to ensure the best design scheme after the change.

\subsection{In-depth design stage of arts and crafts}

In the final stage and in-depth design stage of arts and crafts design, computer assistance plays a decisive role in this stage. Designers need to make final analysis on the schemes determined in the first three stages, and then further improve, check and confirm the data of the threedimensional model[7]. At the same time, they need to use computers to analyze the model data. And finally determine which molding process to choose, the shrinkage ratio of finished product production and the quantity and volume of required raw materials, so as to ensure the success rate of arts and crafts production to the maximum extent and reduce the consumption of raw materials.

\section{Application of Computer Technology in Design of Arts and Crafts}

\subsection{Application of computer technology in sculpture crafts design}

With the continuous development of computer technology, computer technology occupies an important position in all sectors of society at present. Three-dimensional digital technology is gradually integrated into the design process of ceramic crafts. In the design of sculpture crafts, it is particularly important to use three-dimensional digital technology to assist design, which can enhance the creativity of sculpture crafts. In the design of sculpture crafts, 3D digital technology can assist the construction of digital sculpture model, and then render the sculpture model of components, so as to obtain the rendering of $3 \mathrm{D}$ sculpture model. Designers can also use $3 \mathrm{~d}$ smax and other $3 \mathrm{D}$ software to build sculpture models and complete complex modeling design in sculpture design. In sculpture design, designers can use ZBrush software to build the skeleton of the sculpture model, and need to use ZSphere to build the skeleton of the model, and then use different commands including "Rotato", "Scale" and "Move" to add and adjust the angle size and position of the $\mathrm{Z}$ ball. After the final editing, you can use "Rota to" and "Move" to adjust the overall dynamics of the sculpture and complete the model construction[8].

\subsection{Application of computer technology in glass crafts design}

In the design process of glass crafts, computer technology also runs through the whole process, among which $3 \mathrm{D}$ printing technology is widely used. The combination of arts and crafts and 3D technology can create unique coloured glaze crafts. Designers of glass crafts need to create virtual digital models by using 3D modeling software, and directly print paraffin models by using 3D printing technology. After the paraffin model is printed, the next demoulding manufacturing and other subsequent processes are carried out, so that the process of paraffin making seed film in traditional glass manufacturing is replaced. Complex processing links are simplified, which shortens the design and manufacturing cycle, and enables glass designers to try to design and manufacture glass arts 
and crafts with different shapes by using computer 3D printing technology and other technologies, thus broadening the design and manufacturing channels of glass arts and crafts[9].

\subsection{Application of computer technology in ceramic tea set modeling design}

Ceramic tea set is a kind of ceramic handicraft with relatively complex shape. Computer technology is widely used in the modeling design of ceramic tea set, which can assist the design of the curved surface of ceramic tea set. The application of Rhino software can simplify the curved surface design, and at the same time greatly reduce the error of the teapot curved surface rate. Computer threedimensional model can assist the drawing of ceramic tea set, and draw in sequence by using the subordinate relationship between different parts of arc distance. When drawing the curve of silent section, the tools of arc and curve will be used. In order to get the three-dimensional solid modeling of kettle body, the rotational moulding tool can be used. Then, the curve drawing and solid modeling of the spout are carried out. Finally, other details of the ceramic teapot, including the lid and button, are created[10]. After that, the created Chaohu Lake model needs to be carefully checked. Once the damaged surface is found, it should be repaired in time. Using computer software to render the ceramic teapot model, the rendering can simulate the visual effect of the real ceramic tea set, display the animation effect of the ceramic tea set model in an all-round way, and construct the overall coordinated ceramic tea set model, as shown in the following figure:

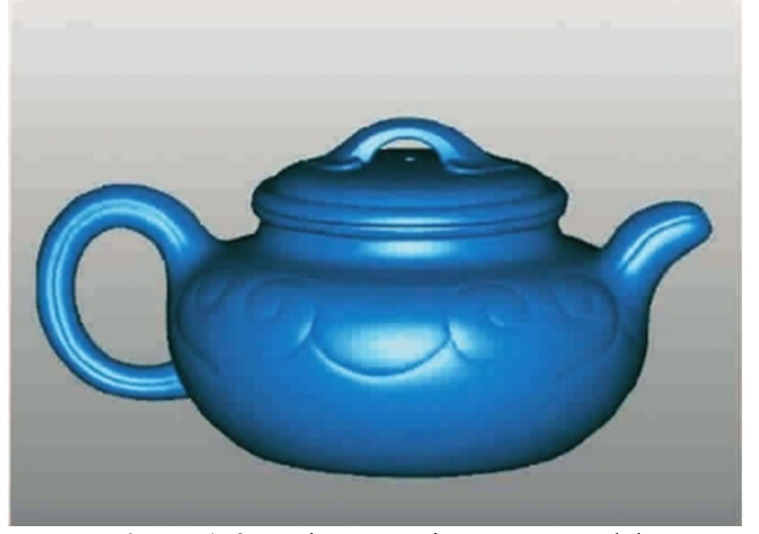

Figure 1. 3D Print Ceramic Tea Set Model

\section{Conclusion}

Looking at the long history of the development of arts and crafts, we find that the expression forms of arts and crafts are different in different times, and the artistic creation means and expression forms are restricted or promoted by different factors. At present, the development and inheritance of art fields are affected by the development of science and technology. With the wide application of computer technology in all walks of life, people's ways of living, working and studying have gradually changed, and the application of computer technology in arts and crafts design has become more and more extensive. The field of arts and crafts design has gradually developed into a bottleneck according to the traditional design and production. Computer technology has brought new opportunities to the development of arts and crafts design, which can enhance the practicality and artistic charm of arts and crafts and be liked by more people.

\section{References}

1. Zhang Mian.Dissemination of Art Works in the Internet Age[J].Beauty \& Times,2021(02): 115-116.

2. Dong Yezi.Literature Review of Traditional Arts and Crafts Inheritance under the Background of New Media[J].Art Education Research,2021(02):50-51.

3. Wang Xingyang, Zhu Yutong.The Importance of Integrating Arts and Crafts in Landscape Design[J].China Place Name,2020(03):37.

4. $\mathrm{Yu} \mathrm{Zhu}$, Yan Ying.Analysis on the Application of Computer-Aided Design in the Innovation and Development of Arts and Crafts[J].Hubei Agricultural Mechanization, 2019(22):65.

5. Mu Jinming, Wang Chunhua.Research on the Application of Computer Technology in the Design of Arts and Crafts[J].Information Recording Materials,2019,20(10):131-133.

6. Tian Yuguo.Application of Computer in Design of Arts and Crafts[J].China Computer \& Communication,2018(08):4-5+8.

7. Wang Bin.Application of New Media in Art and Crafts Painting[J].Youth Magazine,2018(01):49.

8. Zhu Liye.Analysis of Creativity in Contemporary Arts and Crafts Design[J].MING (Attitude),2017(18):63.

9. Peng Chenglu. Research on Internet Communication of Traditional Arts and Crafts Value[D].Chinese National Academy of Arts,2018.

10. Ma Jia.Computer-Aided Teaching of Arts and Crafts[J].Youth Diary: Research on Education and Teaching,2015(10):11. 